\title{
Predictive value of clinical factors through restaging after induction concurrent chemoradiotherapy for locoregionally advanced adenocarcinoma of the esophagus and gastroesophageal junction
}

\author{
Brooke Phillips ${ }^{1}$, David Adelstein ${ }^{1}$, Thomas Rice ${ }^{2}$, Lisa Rybicki ${ }^{3}$, Christina Rodriquez ${ }^{1}$, Gregory \\ Videtic $^{4}$, J errold Saxton ${ }^{4}$, Sudish Murthy ${ }^{2}$, David Mason ${ }^{2}$, Denise Ives ${ }^{1}$ \\ 1. Department of Solid Tumor Oncology, Taussig Cancer Institute, Cleveland Clinic Foundation, Cleveland, Ohio, USA. 2. \\ Department of Thoracic and Cardiovascular Surgery, Heart and Vascular Institute, Cleveland Clinic Foundation, Cleveland, \\ Ohio, USA. 3. Department of Quantitative Health Sciences, Lerner Research Institute, Cleveland Clinic Foundation, \\ Cleveland, Ohio, USA. 4. Department of Radiation Oncology, Taussig Cancer Institute, Cleveland Clinic Foundation, \\ Cleveland, Ohio, USA
}

Correspondence: Brooke E. Phillips. Address: Department of Solid Tumor Oncology, Taussig Cancer Institute, Cleveland Clinic Foundation, 9500 Euclid Ave R35, Cleveland, Ohio 44195, USA. E-mail: brooke.phillips@uchospitals.edu

Received: November 13, 2012

Accepted: December 3, 2012

Online Published: December 27, 2012

DOI : $10.5430 /$ jst.v3n1p48

URL: http://dx.doi.org/10.5430/jst.v3n1p48

\section{Abstract}

Background: Current treatment protocols for locoregionally advanced esophageal cancer add concurrent chemoradiotherapy to surgical resection in an effort to improve curative potential. These approaches are intensive and toxic. This retrospective review was undertaken to identify clinical features after concurrent chemoradiotherapy that might predict for treatment failure.

Methods: 155 patients with locoregionally advanced adenocarcinoma of the esophagus/gastroesophageal junction were treated with concurrent chemoradiation with 96 hour infusions of cisplatin $\left(20 \mathrm{mg} / \mathrm{m}^{2} /\right.$ day) and fluorouracil $\left(1,000 \mathrm{mg} / \mathrm{m}^{2} /\right.$ day) beginning on day 1 of radiation (30 Gy @ 1.5 Gy bid). Surgery followed in 4-6 weeks with identical concurrent chemotherapy planned post-operatively. 75 patients also received 2 years of oral gefitinib Pretreatment staging evaluation was obtained in all patients which included a medical history, physical examination, complete blood count, serum chemistries, chest radiograph, computed tomographic scans of the chest and abdomen, pulmonary function studies, esophagogastroduodenoscopy (EGD) with biopsy, endoscopic ultrasound (EUS), and bronchoscopy if indicated by symptomatology, or by the extent or location of the primary lesion. This also included assessment of symptomatic dysphagia. Approximately 3 weeks after completing induction chemoradiation, all patients underwent restaging evaluation. Using this pretreatment and posttreatment staging information, prognostic factors for freedom from recurrence and overall survival were identified.

Results: The 36 months freedom from recurrence was 31\% and overall survival 32\%. Post-induction change in EGD tumor length and EUS TNM stage did not correlate with outcome. Resolution of symptomatic dysphagia, which occurred in $86 \%$, was the strongest predictor for freedom from recurrence $(p<0.001)$ and overall survival $(p<0.001)$.

Conclusions: EGD and EUS restaging of locoregional disease after induction concurrent chemoradiotherapy did not help to predict recurrence. The persistence symptomatic dysphagia, when coupled with advanced pretreatment stage, is ominous and predicts for incurable disease. Subsequent therapy should be considered palliative.

\section{Key words}

Esophageal cancer, Gastroesophageal junction cancer, Chemoradiation, Adenocarcinoma, Dysphagia 


\section{I ntroduction}

In 2010, there were an estimated 16,640 patients diagnosed with cancer of the esophagus and 14,500 deaths in the United States ${ }^{[1]}$. Even when locoregionally confined, the outcomes after surgery alone have been poor ${ }^{[2-4]}$, reflecting the late clinical presentation of patients with this disease and its propensity for early tumor dissemination ${ }^{[5]}$. In an effort to improve local and systemic disease control, multimodality treatment approaches using perioperative chemotherapy, with or without concurrent radiotherapy, have been intensively explored. Multiple trials and meta-analyses have evaluated chemotherapy, radiation and surgery compared to surgery alone for esophageal cancer ${ }^{[2,4,6-12]}$. Despite conflicting results from individual randomized trials, the meta-analyses have consistently shown a survival advantage with induction concurrent chemoradiotherapy followed by surgery which has emerged as a current standard of care for locoregionally advanced esophageal and gastroesophageal junction (GEJ) cancer.

Surgical resection is a significant intervention with considerable associated morbidity and some mortality. The success of chemoradiation has led to debate about the contribution of this surgery and discussion attempting to define those patients most likely to derive curative benefit from resection. Older clinical trials using concurrent chemoradiation alone have resulted in outcomes which are similar to those achieved in multimodality trials including surgery ${ }^{[13,14]}$. Two randomized trials have directly compared chemoradiotherapy alone to chemoradiotherapy followed by surgery, and both studies failed to show an improved survival with the surgery. The majority of patients in these two studies, however, had squamous cell carcinoma ${ }^{[15,16]}$, an experience which may not apply to current North American experience in which the predominant histopathology is adenocarcinoma ${ }^{[17]}$.

It has also been noted that up to $1 / 3$ of patients will achieve a complete pathologic response after induction chemoradiation. These patients have significantly better survival rates than those with partial or no response ${ }^{[18,19]}$, and the argument can be made that the surgery did not contribute to their successful treatment. Although it is difficult to clinically identify these complete responders after induction, perhaps surgery should only be recommended for those patients with residual disease ${ }^{[20]}$.

Instead of asking which patients might benefit from surgery, we chose to try to better define those patients with locoregionally advanced esophageal cancer who will not be cured with surgery. We report this retrospective analysis of two prospective Cleveland Clinic trials in an effort to determine if there are clinical features from restaging evaluation that might predict those who recur quickly after surgery and would therefore achieve, at best, only palliative benefit from the surgical procedure. The secondary endpoint was to determine the utility of EGD and EUS in restaging after chemoradiation. In order to mirror the current epidemiology of this disease, and eliminate potentially confusing patient heterogeneity, we have limited this analysis to patients with adenocarcinoma.

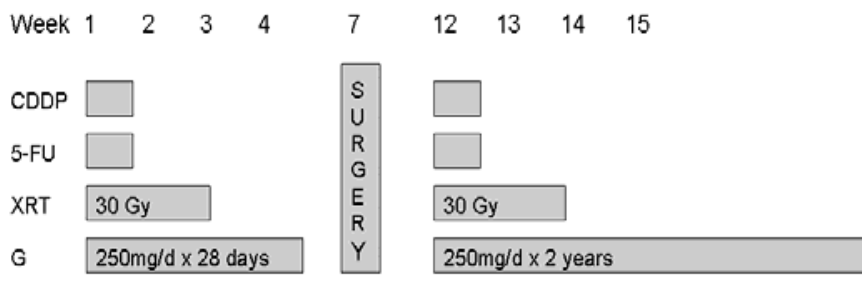

Figure 1. Treatment schema

CDDP: Cisplatin $20 \mathrm{mg} / \mathrm{m}^{2} /$ day continuous IV infusion $\mathrm{d} 1-4$

5-FU: 5-Fluorouracil $1,000 \mathrm{mg} / \mathrm{m}^{2} /$ day continuous IV infusion $\mathrm{d} 1-4$

XRT: $\quad 30$ Gy @ 1.5 Gy BID

G: Gefitinib $250 \mathrm{mg} /$ day po given to 76 patients 


\section{Materials and methods}

Between November 1999 and July 2006, eligible patients with locoregionally advanced cancer of the esophagus or GEJ were entered on one of two consecutive, previously reported Cleveland Clinic trials ${ }^{[21,22]}$. Both trials employed concurrent chemoradiotherapy using 96 hour infusions of cisplatin $\left(20 \mathrm{mg} / \mathrm{m}^{2} /\right.$ day $)$ and fluorouracil $\left(1,000 \mathrm{mg} / \mathrm{m}^{2} /\right.$ day $)$ beginning on day 1 of radiation (30 Gy @ 1.5 Gy bid). Surgery followed in 4-6 weeks with identical concurrent chemoradiotherapy planned post-operatively to a total radiation dose of $60 \mathrm{~Gy}$. The second study only differed from the first by the addition of the oral epidermal growth factor inhibitor gefitinib, 250mg/day, which was given for 2 years (Figure 1).

Eligibility for these clinical trials required a histologically confirmed diagnosis of esophageal carcinoma (squamous cell carcinoma, adenocarcinoma, or mixed adenosquamous carcinoma). Patients with tumors anywhere in the esophagus were eligible including those that extended into the stomach. Inclusion required T3, N1, or M1a disease (based on the staging system of the American Joint Committee on Cancer, 6th edition ${ }^{[23]}$ ), no prior malignancy, no other major medical co-morbidities, and signed informed consent. Both studies were approved and reviewed annually by the Cleveland Clinic Institutional Review Board. Of the 173 patients enrolled on these two trials, 155 had a pathologic diagnosis of adenocarcinoma (or adenosquamous carcinoma) and constitute the data set for this report.

Table 1. Patient and tumor characteristics

\begin{tabular}{|c|c|}
\hline & N (\%) \\
\hline \multicolumn{2}{|l|}{ Age, years } \\
\hline Median (range) & $59(33-76)$ \\
\hline \multicolumn{2}{|l|}{ Gender } \\
\hline Male & 135 (89.4) \\
\hline Female & $16(10.6)$ \\
\hline \multicolumn{2}{|l|}{ Race } \\
\hline White & $147(97.4)$ \\
\hline Black & $3(2.0)$ \\
\hline Asian & $1(0.7)$ \\
\hline \multicolumn{2}{|l|}{ Tumor Location } \\
\hline Mid-esophagus & $4(2.6)$ \\
\hline Distal esophagus & $58(38.4)$ \\
\hline GE junction & 89 (58.9) \\
\hline \multicolumn{2}{|l|}{ Histology } \\
\hline Adenocarcinoma & $148(98.0)$ \\
\hline Adeno-squamous & $3(2.0)$ \\
\hline \multicolumn{2}{|l|}{ Pretreatment stage } \\
\hline Stage II & $52(34.4)$ \\
\hline Stage III & $63(41.7)$ \\
\hline Stage IVA & $36(23.8)$ \\
\hline \multicolumn{2}{|l|}{ Surgery } \\
\hline Underwent resection & 140 (92 7) \\
\hline $\begin{array}{c}\text { Developed metastases } \\
\text { (no surgery) }\end{array}$ & $\begin{array}{l}140(92.7) \\
11(7.3)\end{array}$ \\
\hline \multicolumn{2}{|l|}{ Pathologic Response } \\
\hline Complete response & $8(5.3)$ \\
\hline Partial response & $57(37.7)$ \\
\hline No response & $44(29.1)$ \\
\hline Progressive disease & $42(27.8)$ \\
\hline
\end{tabular}


Pretreatment staging evaluation in all patients included a medical history, physical examination, complete blood count, serum chemistries, chest radiograph, computed tomographic scans of the chest and abdomen, pulmonary function studies, esophagogastroduodenoscopy (EGD) with biopsy, endoscopic ultrasound (EUS), and bronchoscopy if indicated by symptomatology, or by the extent or location of the primary lesion. Fluorodeoxyglucose positron emission tomographic (PET) scanning has been obtained routinely only since 2002 when it became readily available at our institution. As such, these data are incomplete and not included. Approximately 3 weeks after completing induction chemoradiation, all patients underwent restaging evaluation. This evaluation included repeat pulmonary function testing, computerized tomographic scanning, upper endoscopy, esophageal ultrasound, and a reassessment of their symptomatic dysphagia.

Data collected from these 155 patients with adenocarcinoma included response of their symptomatic dysphagia. Dysphagia was measured using a grading system, 1 through 4. Grade 1 was recorded for those with symptoms at diagnosis but whose symptoms completely resolved after chemoradiation. Symptomatic resolution required patients to be tolerating a normal diet without dysphagia and to have an Eastern Cooperative Oncology Group performance status of 0. Grade 2 was measured as symptoms present at diagnosis and partially resolved after chemoradiation. Grade 3 identified those with symptoms present at diagnosis but not changed with treatment. Grade 4 identified those with symptoms that had worsened after chemoradiation. This data was obtained by the primary investigators at follow-up assessment. Other data collected included pretreatment and post-induction treatment tumor length, change in tumor length, pretreatment and post-induction treatment EUS-assigned TNM classification and tumor stage, as well as change in TNM classification and tumor stage.

\section{Statistical methods}

Cox proportional hazards analysis was used to identify univariable risk factors for recurrence. Stepwise Cox analysis with a variable entry criterion of $P<0.10$ and a variable retention criterion of $P<0.05$ was used to identify multivariable risk factors. All results are presented as the hazard ratio (HR), 95\% confidence interval (CI) for the HR, and the corresponding $P$-value.

Freedom from recurrence (FFR) and overall survival (OS) were estimated using the Kaplan-Meier method. The event corresponding to FFR is disease recurrence. Patients who were not resected were considered to have a recurrence at time 0 , and thus had FFR of 0 . The event corresponding to OS is all-cause mortality. The timing of both outcomes was calculated relative to the treatment start date.

Cox analysis was also used to assess recurrence and death as time-to-event outcomes. Recurrence and death were assessed as binary outcomes at 24 months. Logistic regression analysis was used to identify univariable risk factors of possible importance for recurrence and death including symptom response, pre-treatment tumor length, pretreatment tumor TNM classification, pretreatment tumor stage, posttreatment TNM classification, posttreatment stage, change in TNM, and change in stage. Multivariable models were then developed using those univariable factors. Logistic regression results are presented as the odds ratio (OR), 95\% confidence interval (CI) for the OR, and corresponding $p$-value.

\section{Results}

Of the 155 patients included in this analysis, 4 patients became medically unresectable during induction chemoradiotherapy and were not analyzed. The remaining 151 patients were predominately male, and had a median age of 59 years. Patient and tumor characteristics are detailed in Table 1. All had some degree of dysphagia at presentation. Dysphagia was compared for those with resolved symptoms (grade 1) vs. unresolved symptoms (grade 2-4).

After chemoradiation, 140 patients underwent resection and 11 developed anatomically unresectable disease. At the time of surgery, 8 patients (5.3\%) had achieved a pathologic complete response and 57 patients (37.7\%) had a partial response. With a median follow-up of 62 (range 38-105) months, 3-year FFR was 31\% and OS 32\%. 
Table 2. Multivariable risk factors for recurrence and death

\begin{tabular}{llll}
\hline Variable & HR $^{*}$ & $\mathbf{9 5 \%} \mathbf{C I}^{* *}$ & $\boldsymbol{P}$ \\
\hline $\begin{array}{l}\text { Recurrence: } \\
\text { Symptom response }\end{array}$ & & & $<0.001$ \\
$\quad \begin{array}{l}\text { Unresolved/resolved } \\
\text { Post-treatment N-stage }\end{array}$ & 2.91 & $1.72-4.94$ & 0.024 \\
$\quad$ N1/N0 & 1.59 & $1.06-2.38$ & $<0.001$ \\
$\begin{array}{l}\text { Death: } \\
\text { Symptom response } \\
\quad \text { Unresolved/resolved }\end{array}$ & 2.50 & & 0.049 \\
$\begin{array}{l}\text { Pre-treatment tumor length } \\
\text { Per } 1 \text { cm increase }\end{array}$ & 1.08 & $1.55-4.03$ & \\
\hline
\end{tabular}

Figure 2. Outcomes by symptom resolution freedom from recurrence

Figure 3. Outcomes by symptom resolution - overall survival
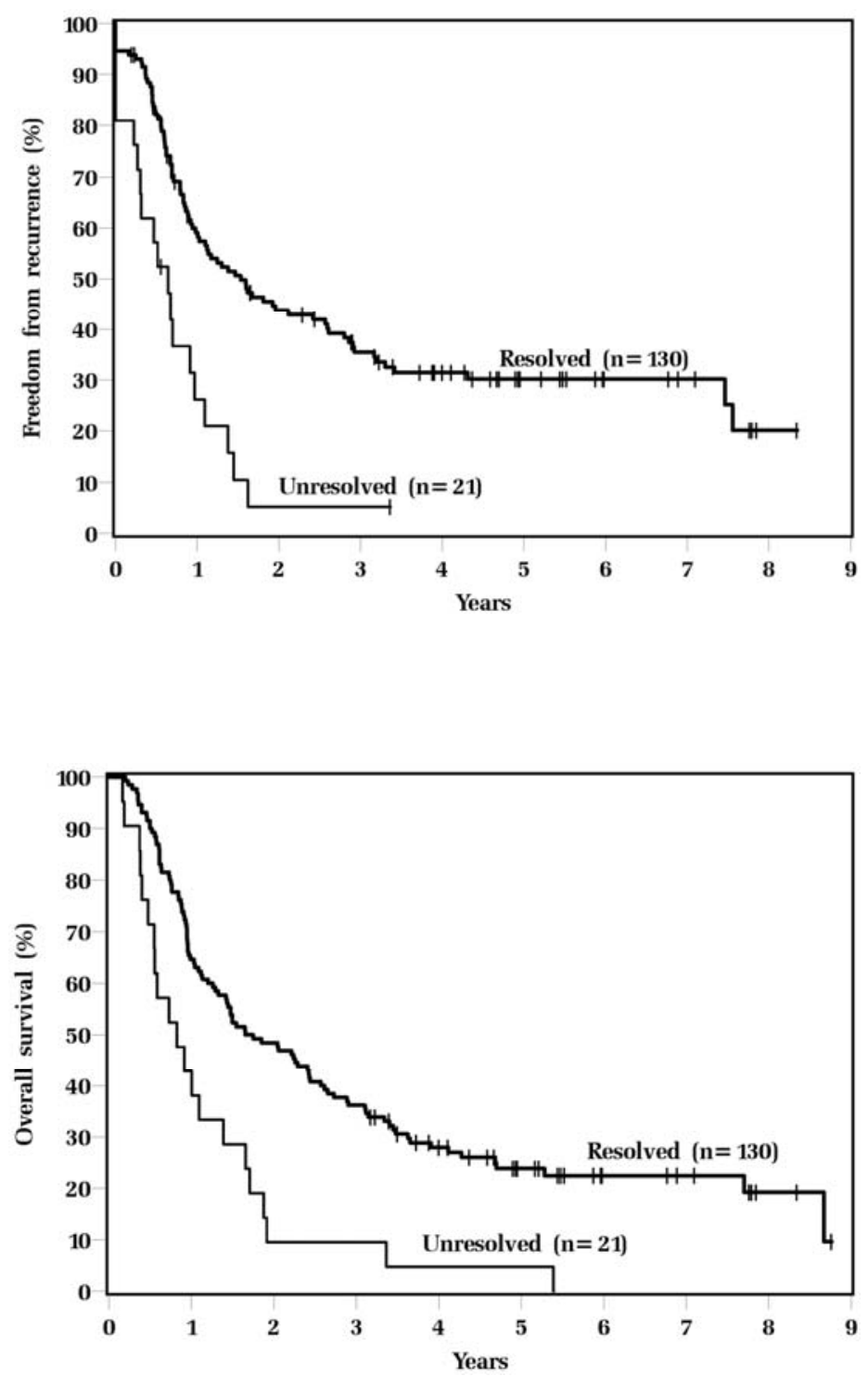
Resolution of symptomatic dysphagia, which occurred in $86 \%$, and unresolution of symptomatic dysphagia was the strongest predictor for both outcomes with a HR 2.91 (95\% CI 1.72 -4.92; $p<0.001$ ) for recurrence, and a HR 2.50 (95\% CI 1.55-4.03; $p<0.001$ ) for overall survival (Table 2). In addition, post-treatment node positivity was associated with increased recurrence (HR 1.59, 95\% CI 1.06-2.38, $p=0.024$ ), and longer pre-treatment tumor length was associated with worse survival (HR 10.8, 95\% CI 1.00-1.16, $p=0.049$ ).

These outcomes were next evaluated at 24 months using logistic regression. The OR for recurrence and death for patients with unresolved vs. resolved symptoms were 8.63 (95\% CI 1.88-39.6; $p<0.006)$ and 8.89 (95\% CI 1.97-40.1; $p<0.004$ ), respectively (Table 3) (Figures 2 and 3). Pretreatment stage also proved important in predicting these 24 month outcomes. Using this model we can predict that patients with unresolved symptoms and pretreatment stage III/IVa disease will have a 24-month recurrence rate of $100 \%$ and an OS of $7 \%$. Conversely, stage II patients with symptomatic resolution will have a 24 -month recurrence rate of $45 \%$ and OS of $57 \%$. Change in tumor length or EUS staging after induction did not predict recurrence or overall survival.

Table 3. Risk factors for 24-month outcomes

\begin{tabular}{llll}
\hline & $\mathbf{O R}^{*}$ & $\mathbf{9 5 \%} \mathbf{C I}^{* *}$ & $\mathbf{P}$ \\
\hline $\begin{array}{l}\text { Recurrence: } \\
\text { Symptom response } \\
\text { Unresolved/resolved }\end{array}$ & & & \\
Pre-treatment stage & 8.63 & $1.88-39.6$ & 0.006 \\
$\quad$ III/II & 2.10 & & \\
IVA/II & 4.89 & $0.96-4.57$ & 0.06 \\
Death: & & $1.82-13.1$ & 0.002 \\
Symptom response & & \\
$\quad$ Unresolved/resolved & 8.89 & $1.97-40.1$ & 0.004 \\
Pre-treatment stage & & & \\
III/II & 1.32 & $0.61-2.84$ & 0.48 \\
IVA/II & 2.78 & $1.08-7.10$ & 0.033 \\
\hline
\end{tabular}

\section{Discussion}

Multiple randomized trials have been conducted to explore the importance of chemotherapy, radiation and surgery for esophageal cancer. These studies have often been underpowered, and compromised by inadequate clinical staging and patient populations with both adenocarcinoma and squamous cell carcinoma. While these compromises clearly reflect the inherent difficulties of both studying and treating this disease, they have also resulted in limited and conflicting conclusions.

A comparison of two of the most recent randomized trials is illustrative. Burmeister et al. assigned patients with adenocarcinoma or squamous cell carcinoma of the esophagus to chemoradiation and surgery or surgery alone ${ }^{[6]}$. Neither progression free survival nor OS differed between the groups. Subgroup analysis revealed that patients with squamous cell carcinoma had an improved progression free survival with chemoradiation compared to those with non-squamous histology although the study was not powered for this comparison. Criticisms of this study include the use of only one cycle of chemotherapy and a total radiation dose of only $35 \mathrm{~Gy}$.

CALBG 9781 was originally designed to enroll 500 patients in order to evaluate trimodality therapy vs. surgery alone for stage I-III esophageal cancer ${ }^{[10]}$. This trial only slowly accrued and was closed after only 56 patients had enrolled (42 with adenocarcinomas, 14 with squamous cell carcinoma). An intent-to-treat analysis demonstrated a median survival of 4.48 
vs. 1.79 years and a 5 -year survival of $39 \%$ vs. $16 \%$ in favor of trimodality therapy, although the $95 \%$ confidence intervals for both observations overlapped. The major limitation of this study was the small sample size, weakening any conclusions which might be drawn.

Meta-analyses however have provided a clearer and more consistent answer, despite the heterogeneity of patient populations studied, and the variability in the treatment regimens. In the Urschel and Vasan meta-analysis, there was a nonsignificant trend towards improved survival with concurrent or sequential chemoradiotherapy and surgery compared to surgery alone ${ }^{[12]}$. When only the trials using concurrent chemoradiotherapy were analyzed, the three-year survival benefit was statistically significant (OR 0.45, $95 \%$ CI 0.26 to 0.79). In the meta-analysis from Gebski et al, there was also an improvement in all-cause mortality after neoadjuvant chemoradiotherapy compared to surgery alone (HR 0.81, 95\% CI $0.70-0.93 ; p=0.002$ ), and corresponding to a $13 \%$ absolute improvement in survival at 2 years ${ }^{[24]}$. The benefit was similar for both squamous cell and adenocarcinoma.

Two randomized trials have addressed the contribution of surgery to multimodality management by comparing definitive chemoradiotherapy with induction chemoradiotherapy followed by surgery in patient populations with predominately squamous cell carcinoma ${ }^{[15,16]}$. Neither of these studies demonstrated an improvement in overall survival from the addition of surgery, despite an improvement in local control. It appeared from these trials that any potential benefit from tumor resection may have been lost by the additional peri-operative mortality.

Even when surgery is performed at a high-volume center, where mortality rates of less than 5 percent are now the rule, there is still significant morbidity with esophageal resection ${ }^{[25]}$. Respiratory and/or cardiac complications can be significant. Complications are often increased in older patients or in the presence of associated comorbidity. Clearly both the morbidity and the mortality from this procedure increase at low-volume institutions ${ }^{[26]}$.

It is therefore critical to determine which patients are most likely to derive curative benefit from resection after chemoradiation. In the Urba trial, pathologic complete responders had a significantly better three-year survival when compared to patients with residual tumor at surgery $(64 \% \text { versus } 19 \%)^{[11]}$. This observation raises the question about the importance of resection in the absence of residual disease, even though identifying these pathologic complete responders before surgery is problematic ${ }^{[20]}$.

Instead of asking who might benefit from surgery, we chose to ask if there are presurgical clinical features which could identify those patients destined to recur after treatment who are unlikely to be cured with surgery. Such patients, if identifiable, could be approached with palliative intent.

The strength of this retrospective analysis is that all patients had adenocarcinoma, all were consistently staged and all received the same chemoradiotherapy before surgery. Of the 151 patients with adenocarcinoma, 140 underwent resection and 11 developed unresectable disease. Our results reveal that the strongest presurgical predictor of recurrence and decreased survival was the persistence of symptomatic dysphagia after chemoradiation. One can speculate that persistent symptoms reflect more residual tumor predicting for a reduced ability to successfully ablate the tumor and a greater risk of metastases. More likely however, is that the persistence of symptoms (and persistence of tumor) is only a clinical marker of a lack of response to chemoradiotherapy. Our results also indicate that EGD and EUS restaging of locoregional disease after induction concurrent chemoradiotherapy provides little useful information. Only persistent node positivity after induction therapy was associated with an increased risk of recurrence [HR 1.59 (95\% CI 1.06-2.38; $p=0.024)$ ].

Given that this is a retrospective analysis of two prospective studies, our conclusions might be subject to response bias from the patient or investigator when obtaining information about symptom response. It should also be noted that this Cleveland Clinic protocol for chemoradiation includes chemoradiation given both before and after surgery. The pre-operative doses of both the radiation and chemotherapy are lower than those used in most other treatment schedules. 
This explains our pathologic complete response rate of only 5.3\%, but may also help explain why the presurgical clinical stage did not clearly predict early recurrence.

In conclusion, persistence of symptomatic dysphagia after induction, when coupled with advanced pretreatment stage at diagnosis is highly predictive of treatment failure. Any subsequent therapy should be considered palliative.

\section{Competing interests}

Dr. Adelstein receives research support from AstraZeneca Pharmaceuticals and Sanofi-Aventis Inc which did not provide financial support for this research.

\section{References}

[1] Jemal A, Siegal R Xu J et al. Cancer Statistics, 2010. CA Cancer J Clin. 2010; 60(5), 277-300. PMid:20610543 http://dx.doi.org/10.3322/caac.20073

[2] Bosset JF, Gignoux M Triboulet JP et al. Chemoradiotherapy followed by surgery compared to surgery alone in squamous-cell cancer of the esophagus. N Engl J Med. 1997; 337: 161. PMid:9219702 http://dx.doi.org/10.1056/NEJM199707173370304

[3] Urba S, Orringer M Turrisi A et al. Randomized trial of preoperative chemoradiation versus surgery alone in patients with locoregional esophageal carcinoma. J Clin Oncol. 2001; 19(2): 305-313. PMid:11208820

[4] Walsh T, Noonan N Hollywood D et al. A comparison of multimodal therapy and surgery for esophageal adenocarcinoma. N Engl J Med. 1996; 335: 462. PMid:8672151 http://dx.doi.org/10.1056/NEJM199608153350702

[5] Jemal A, Siegel R Ward E et al. Cancer statistics, 2009. Jemal A; Siegel R; Ward E; Hao Y; Xu J; Thun MJ SO. CA Cancer J Clin. 2009 Jul-Aug; 59(4): 225-49. PMid:19474385 http://dx.doi.org/10.3322/caac.20006

[6] Burmeister B, Smithers B Gebski V et al. Surgery alone versus chemoradiotherapy followed by surgery for resectable cancer of the esophagus: a randomized controlled phase III trial. Lancet Oncol. 2005; 6: 659. http://dx.doi.org/10.1016/S1470-2045(05)70288-6

[7] Gebski V, Burmeister B Smithers B et al. Survival benefits from neoadjuvant chemoradiotherapy or chemotherapy in esophageal carcinoma: a meta-analysis. Lancet Oncol. 2007; 8: 226. http://dx.doi.org/10.1016/S1470-2045(07)70039-6

[8] Le Prise E, Etienne PL Meunier B et al. A randomized study of chemotherapy, radiation therapy, and surgery versus surgery for localized squamous cell carcinoma of the esophagus. Cancer. 1994; 73: 1779. http://dx.doi.org/10.1002/1097-0142(19940401)73:7<1779::AID-CNCR2820730702>3.0.CO;2-T

[9] Nygaard K, Hagen S Hansen HS et al. Preoperative radiotherapy prolongs survival in operable esophageal carcinoma: a randomized, multicenter study of preoperative radiotherapy and chemotherapy - the second Scandinavian trial in esophagus cancer. World J Surg. 1992; 16: 1104. http://dx.doi.org/10.1007/BF02067069

[10] Tepper J, Krasna M Niedzwiecki D et al. Phase III trial of trimodality therapy with cisplatin, fluorouracil, radiotherapy, and surgery compared to surgery alone for resectable esophageal cancer. J Clin Oncol. 2008; 26: 1086. PMid:18309943 http://dx.doi.org/10.1200/JCO.2007.12.9593

[11] Urba S, Orringer M Turrisi A et al. Randomized Trial of Preoperative Chemoradiation Versus Surgery Alone in Patients with Locoregional Esophageal Carcinoma. J Clin Oncol. 2001; 19: 305. PMid:11208820

[12] Urschel J, Vasan H. A meta-analysis of randomized controlled trials that compared neoadjuvant chemoradiation and surgery to surgery alone for resectable esophageal cancer. Am J Surg. 2003; 185(6): 538-543. http://dx.doi.org/10.1016/S0002-9610(03)00066-7

[13] Herskovic A, Marz K al-Sarraf M et al. Combined chemotherapy and radiotherapy compared with radiotherapy alone in patients with cancer of the esophagus. N Engl J Med. 1992; 326(24): 1593. PMid:1584260 http://dx.doi.org/10.1056/NEJM199206113262403

[14] Wobbes T, Baron B Paillot B et al. Prospective randomized study of split-course radiotherapy versus cisplatin plus split-course radiotherapy in inoperable squamous cell carcinoma of the esophagus. Eur J Cancer. 2001; 37(4): 470. http://dx.doi.org/10.1016/S0959-8049(00)00399-3

[15] Bedenne L, Michel P Bouche $\mathrm{O}$ et al. Chemoradiation followed by surgery compared with chemoradiation alone in squamous cancer of the esophagus: FFCD 9102. J Clin Oncol. 2007; 25(10): 1160-1168. PMid:17401004 http://dx.doi.org/10.1200/JCO.2005.04.7118

[16] Stahl M, Stuschke M Lehmann N et al. Chemoradiation with and without surgery in patients with locally advanced squamous cell carcinoma of the esophagus. J Clin Oncol. 2005; 23(10): 2310-2317. PMid:15800321 http://dx.doi.org/10.1200/JCO.2005.00.034 
[17] Bollschweiler E, Wolfgarten E Gutschow C et al. Demographic variations in the rising incidence of esophageal adenocarcinoma in white males. Cancer. 2001; 92(3): 549-555. http://dx.doi.org/10.1002/1097-0142(20010801)92:3<549::AID-CNCR1354>3.0.CO;2-L

[18] Reynolds JV, Muldoon C Hollywood D et al. Long-term outcomes following neoadjuvant chemotherapy for esophageal cancer. Ann Surg. 2007; 245: 707-716. PMid:17457163 http://dx.doi.org/10.1097/01.sla.0000254367.15810.38

[19] Rohatgi R, Swisher S Correa A et al. Characterization of pathologic complete response after preoperative chemoradiotherapy in carcinoma of the esophagus and outcome after pathologic complete response. Cancer. 2005; 104: 2365-2372. PMid:16245310 http://dx.doi.org/10.1002/cncr.21439

[20] Swisher S, Erasmus J Correa A et al. Utility of PET, CT, and EUS to identify pathologic responders in esophageal cancer. Ann Thorac Surg. 2004; 78(4): 1152-1160. PMid:15464463 http://dx.doi.org/10.1016/j.athoracsur.2004.04.046

[21] Adelstein D, Rice T Rybicki L et al. A Phase II Trial of Accelerated Multimodality Therapy for Locoregionally Advanced Cancer of the Esophagus and Gastroesophageal Junction. Am J Clin Oncol. 2007; 30: 172-180. PMid:17414467 http://dx.doi.org/10.1097/01.coc.0000251243.58048.12

[22] Rodriquez C, Adelstein D Rice T et al. A Phase II Study of Perioperative Concurrent Chemotherapy, Gefitinib, and Hyperfractionated Radiation Followed by Maintance Gefitinib in Locoregionally Advanced Esophagus and Gastroesophageal Junction Cancer. J Thorac Oncol. 2010; 5: 229-235. PMid:20009775 http://dx.doi.org/10.1097/JTO.0b013e3181c5e334

[23] Greene F PDFIeal. AJCC Cancer Staging Manual (6th Edition). Springer, 2002.

[24] Gebski V, Burmeister B Smithers B et al. Survival benefits from neoadjuvant chemoradiotherapy or chemotherapy in oesophageal carcinoma: a meta-analysis. Lancet Oncol. 2007; 8(3): 226-234. http://dx.doi.org/10.1016/S1470-2045(07)70039-6

[25] Swisher SG, Deford L, Merriman KW, Walsh GL, Smythe R, Vaporicyan A, Ajani JA, Brown T, Komaki R, Roth JA, and Putnam JB. Effect of operative volume on morbidity, mortality, and hospital use after esophagectomy for cancer. J Thorac Cardiovasc Surg. 2000; 119(6): 1126-1132. PMid:10838528 http://dx.doi.org/10.1067/mtc.2000.105644

[26] Lagarde SM, Reitsma JB, Maris AK, van Berge Henegouwen MI, Busch OR, Obertop H, Zwinderman AH, and van Lanschot JJ. Preoperative prediction of the occurrence and severity of complications after esophagectomy for cancer with use of a nomogram. Ann Thorac Surg. 2008; 85(6): 1938-1945. PMid:18498798 http://dx.doi.org/10.1016/j.athoracsur.2008.03.014 